\title{
Research on the Application Strategy of Mixed Teaching Mode of Visual Communication Design Specialty in Colleges and Universities Based on Multidimensional Interaction
}

\author{
Min Huang ${ }^{1}$, Dandan Luo ${ }^{1, *}$ \\ ${ }^{1}$ South China Normal University, Guangzhou,510631, China
}

\begin{abstract}
With the change of teaching methods and the continuous advancement of educational reform, blended teaching has become a new trend in higher education. The application of network information technology in classroom has changed the traditional learning environment, teaching structure and learning methods, and improved teaching efficiency. In the information age, the talent training of visual communication design major must keep pace with the times, aiming at training innovative talents and practical talents. According to this goal, this paper puts forward a mixed teaching mode based on multi-dimensional interaction and massive open online course platform to make up for the shortcomings in current teaching. It has a certain guiding effect on the practical teaching of visual communication design specialty.
\end{abstract}

\section{Introduction}

With the development of economy and the change of times, people have higher and higher requirements for the quality of life and more pursuit for the experience of visual enjoyment. However, it is not so easy to train high-level visual communication design talents in a short time. It is necessary to find out the defects of the current visual specialty and pay attention to the cultivation of innovative and practical talents [1]. Therefore, we should establish a new teaching concept, attach importance to the application of information technology, and carry out mixed teaching based on online education platform to better improve the teaching quality of this major.

Multidimensional interactive teaching is based on activity teaching theory, people-oriented, student-centered, respecting individual learning rules, giving full play to individual mutual influence and interaction advantages, and promoting the efficient development of teaching activities under the organization and guidance of teachers [2-3]. Blended learning is an effective way of learning, which combines a variety of mixed strategies, such as online and offline, flipping classroom, traditional classroom, learning and learning, school learning, lifelong learning and so on. The mixed strategy of "learning" and "learning" explains the connotation of blended learning, organically combines online and face-to-face learning with repeated practice and research, and emphasizes that students are the main body of learning, which can ensure the effective development of curriculum teaching [4]. Therefore, aiming at the research of mixed teaching mode for visual communication design specialty, this paper studies the application strategy of mixed teaching mode for visual communication design specialty in colleges and universities based on multi-dimensional interaction.

\section{Multidimensional interactive teaching mode}

Multidimensional interactive teaching mode is a studentcentered classroom teaching mode, which constructs classroom teaching in different ways, such as teachers and students, students and students, learning interest groups and so on. Starting from the language itself, let the students experience the charm of language constantly, and enhance the accumulation of language knowledge, so as to improve students' listening, speaking, reading and writing skills. Its outstanding feature is people-oriented, stimulating individual interest in learning, and giving play to individual learning initiative and initiative. Its advantages mainly lie in [5]:

(1) Cultivate students' sense of participation

Multi-dimensional interactive teaching mode can do just that. Teachers organize the interaction between students and between teachers and students in class by taking advantage of the situation, and create situations, so that students can participate in various activities carried out in the classroom teaching process as masters, give full play to their initiative, and then activate the learning atmosphere and improve learning efficiency.

(2) Stimulate students ' interest in learning

Interest can greatly stimulate learners' potential. Learning with interest or learning passively has obvious differences in learning effects. By exploring and learning knowledge with interest, learners are more motivated, happier and more focused, so that the initiative of doing things can be promoted and the potential of individuals 
can be brought into full play to the greatest extent. In the teaching situation set by teachers and the interaction between students, students can purposefully search for relevant information, and then show the results in the classroom in the teaching situation. After being recognized by teachers and classmates, they will gain a short-term sense of accomplishment, which will greatly stimulate students' interest in learning and then devote themselves to learning with greater enthusiasm.

(3) Cultivate students' awareness of cooperation and communication

People who are good at cooperation and communication can not only find fun in study, work and life, but also promote the willingness of further communication and cooperation, and finally achieve the successful development and realization of study and work. In the multi-dimensional interactive teaching mode, teachers can use classroom teaching to create situations and provide certain time and space for students to communicate and cooperate independently. Students can cooperate, inspire and learn from each other under the task drive, successfully complete classroom learning tasks, and then cultivate the awareness of cooperation and communication.

\section{Teaching structure under the mixed teaching mode}

\subsection{Teaching elements}

Teachers, students, teaching content and media composition, as the structural elements of the mixed teaching mode, constitute a unity and complete the teaching task together. In Figure 1, teachers are not only the designers of teaching content and teaching process, but also the guides and controllers of learning process. They should master students, teaching content and teaching forms as a whole, and tailor teaching content, teaching forms and communication methods for students. Teachers are not only organizers of teaching process, but also cultivators of students' good sentiments [6].

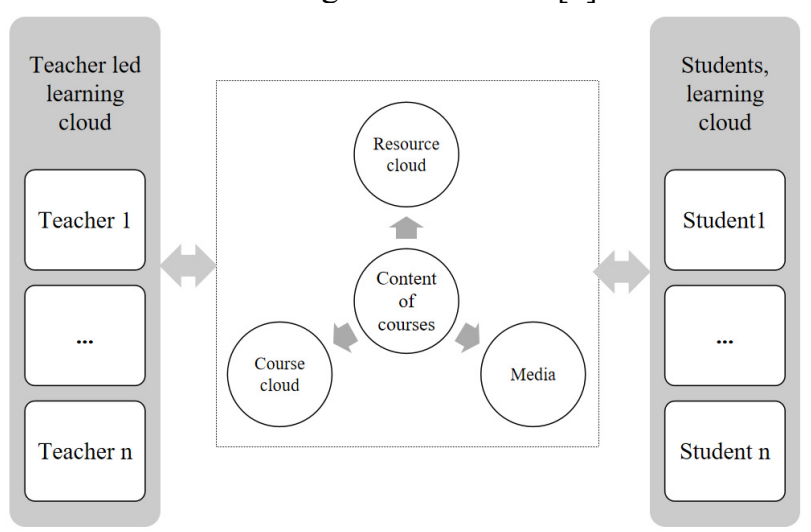

Fig 1. Elements map of teaching structure

In blended learning, students are the main body of learning under the guidance of teachers, and they are the active constructors of knowledge meaning. They have a large number of learning resources designed and controlled by teachers. Through online courses to strengthen teacher-student interaction, face-to-face class situations bring teachers and students closer to direct communication [7]. Students acquire knowledge from various terminals, learning objects and teaching resources. Three-dimensional and omni-directional teaching resources meet various needs of "teaching" and "learning", and are flexible, open and dynamic.

\subsection{Teaching interaction}

In blended learning, teachers and students can interact in class, or "guide" and "learn" the key points and difficulties repeatedly through online courses and video materials. There are abundant means and channels for publishing and obtaining learning resources. Learning activities are not limited by time and space, and can make full use of fragmentation time. See Figure 1 for the interaction among various elements.

The interaction between teachers and students is a mixture of offline face-to-face interaction, online group chat and single chat. The interaction between students and teaching content is the key link of blended teaching, and the learning resources of blended teaching are carefully selected by teachers, which are instructive and targeted. The interaction between learning task groups promotes mutual learning and cultivates the spirit of teamwork. There are more offline discussions among team teachers than online discussions, which is conducive to learning and learning [8-9].

\section{Shortcomings of current teaching of visual communication specialty}

From the perspective of visual communication design majors offered by many universities in China, there are still some shortcomings in the teaching, mainly in the teaching mode and teaching practice. The following is a brief analysis of some of them.

\subsection{Backward teaching mode}

Nowadays, in the teaching process of visual communication design major, the traditional teaching methods are still the main ones, with teachers explaining and students practicing after class. However, with the progress of science and technology and the change of market demand, it is difficult for this teaching mode to cultivate high-quality students who meet the market demand, nor can it meet the needs of students. The overall teaching quality is not high, and there is still a gap between the level of students trained and the needs of employers, so the employment of students has become the main problem.

\subsection{The overall quality of teachers needs to be improved}

With the continuous progress of society, the level of science and technology is getting higher and higher, but some teachers' abilities are still in place, and the 
knowledge and technology they impart to students are limited. Teachers' teaching level is determined by their own professional knowledge and comprehensive quality. When their own knowledge reserves are limited, their teaching level is limited and their teaching ability is limited. Teachers can only use their original experience and knowledge to teach professionally. However, this situation obviously cannot keep up with the trend of the times, and the knowledge acquired by students cannot keep up with the pace of the times.

\subsection{Lack of practice}

Visual communication major is an application type major, so practical application can't be ignored in teaching. However, in actual teaching, some colleges and universities seldom pay attention to the practical training of this major, and students have very few practical opportunities. The practical opportunities that can be obtained are also assignments assigned by some teachers, which cannot be called real practice. Therefore, students lack a deep understanding of their own abilities, and teachers can't get real feedback on learning effects.

\subsection{Textbooks are outdated}

Visual communication major is an application-oriented major, so both course content and teaching content should change with the changes of the times. However, due to the limitation of practical conditions, the teaching materials used in the course can not be updated in time, and the contents of the teaching materials are still the same. In this case, the content of students' learning can't keep up with the trend of the times, and the knowledge and technology they have learned are old and can't meet the needs of future jobs, so it is difficult to get employment.

\section{Application strategy of mixed teaching mode for visual communication design specialty under multi-dimensional interaction}

As a teaching method, online and offline interactive teaching method came into being under the background of Internet. It has made some attempts and breakthroughs in the combination of theory and practice, the diversification of educational subjects, the transformation of educational time and space, and the dynamic teaching mode.

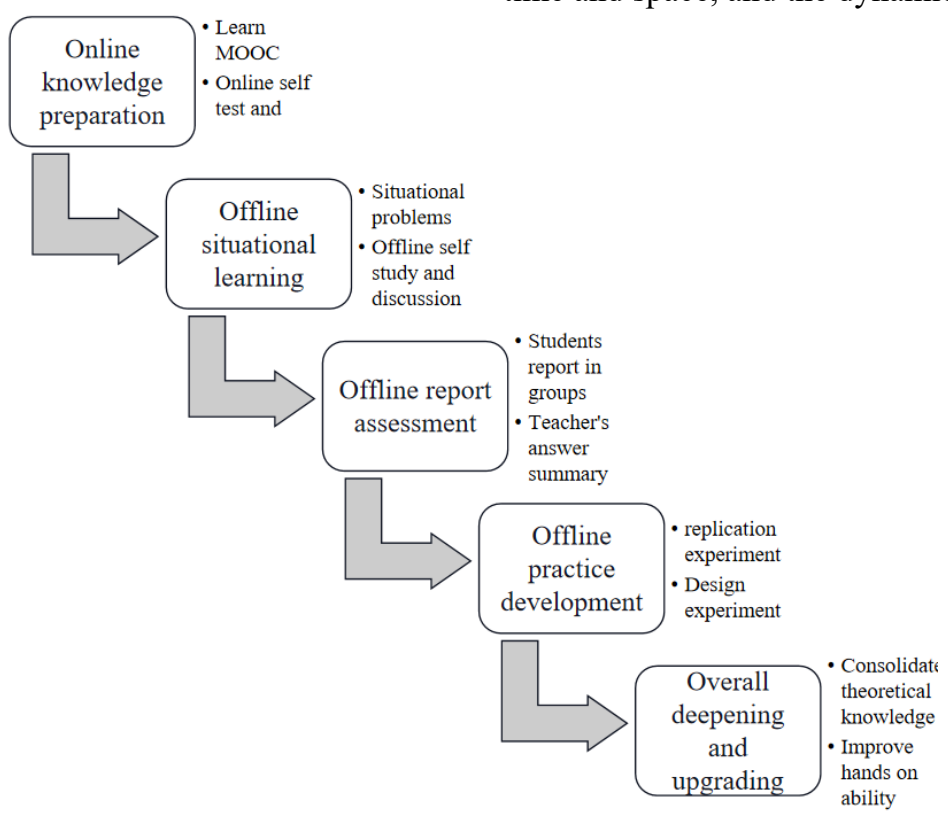

Fig 2. Hybrid teaching mode integrating online and offline teaching

This reform is based on the guiding ideology of "student-centered", with MOOC as the carrier and situational problems as the driving force, aiming at promoting students' autonomous learning and improving students' practical ability. Fig. 2 is a mixed teaching mode integrating online and offline teaching.

\subsection{Interaction of various factors in offline classroom}

The offline teaching method mainly uses classroom teaching resources to introduce basic theories, basic viewpoints, basic methods, teaching concepts and learning methods. The two teaching methods complement each other and play different roles. From the perspective of educational psychology, they can play a role that a single teaching method cannot play. Long-term single teaching method will produce aesthetic fatigue and poor teaching effect.

Offline classroom teaching and online learning are integrated with each other, with the aim of refining key points, analyzing difficulties, solving doubts, broadening ideas and expanding horizons, so as to promote the consolidation and mastery of knowledge and maximize the teaching effect.

The offline interactive classroom teaching must meet the following three teaching requirements. First, it should meet the intensive teaching of basic knowledge. Second, to meet the needs of open knowledge, and third, to meet the needs of practical teaching of applied knowledge. Through case teaching, students' thinking space can be effectively expanded, and students can realize thinking 
innovation on the basis of traditional cases. As far as the training goal of contemporary visual communication talents is concerned, the key lies in whether thinking can keep pace with the times and realize innovation. Innovation plays an important role in visual communication design works, which is a decisive factor for the success or failure of visual communication design works and an effective way to train visual communication talents.

\subsection{Interaction between online and offline teaching, classroom teaching and extracurricular learning}

The online and offline interactive teaching method also gives us a new observation perspective in the combination of theory and practice. Online and offline interactive teaching method is a relatively new teaching method. This method is an innovation and optimization of traditional teaching methods, which can ease the tense classroom atmosphere, create a lively classroom teaching environment, guide students to combine theory with reality, and make knowledge look richer, fuller and more textured. However, the online and offline interactive teaching rules have changed. There are two teaching subjects, one teaching object and one main teaching medium in teaching, namely, the main body of teaching is teachers, the resources of internet teachers, the object of teaching is students, and the medium of teaching is lectures.

For the study of video, audio and other materials online, group discussions and notes are set up for inspection, and discussion and answer of questions can also be interspersed during the playing of the study materials, or simple tests can be carried out. You can also choose different forms such as video chat, conference and discussion to communicate with students under the menu "Interactive Classroom". There is also an effective monitoring method to check students' attendance and online rate by initiating check-in with check-in code.

A large amount of new product design information must be used for reference and applied in the classroom, as the educational reference information and design reference elements of daily teaching. At the same time, students must master forward-looking knowledge, so that they can have practical and innovative professional skills. Based on this, the mixed teaching should be based on the online massive open online course platform. Teachers must analyze students' learning situation in time, including learning progress, learning difficulties, collaboration and error-prone points, and adjust classroom teaching according to the analysis results. In the process of teaching students, both teachers and students are very important. However, teachers must pay attention to their teaching concepts in classroom teaching, constantly update and optimize them, find their own position in classroom reform, recognize their own importance, control the teaching process and grasp their role orientation.

Teachers use various multimedia technologies to answer students' doubts and discuss with students. This kind of discussion and communication is more in-depth, which makes students feel the joy of acquiring knowledge in autonomous learning, and gradually transforms traditional passive learning into mixed teaching of autonomous learning, thus realizing the fundamental change of teaching mode. It must be noted that teachers should pay attention to reminding students of pre-class preparation and urge students to study independently.

\subsection{Interaction between practice and theory}

Increasing the practical teaching time is the most important thing in the reform of higher education system in China. According to the visual communication design major, combining the interaction between teachers and students, students' communication and interaction, and various group interaction modes, the teaching mode is developed concretely. The main purpose of this kind of model is to guide students to participate in learning, and strive to cultivate their awareness of autonomous learning and cultivate their interest in learning visual communication design; In addition, this kind of model will also make students realize the fun of learning and selfcomprehend the satisfaction of actual achievements.

First of all, according to the actual situation of the school, the school should scientifically set up visual communication design courses, increase practical teaching courses, and constantly enrich practical teaching contents to provide students with high-quality practical platforms; Secondly, the school attaches importance to the practical teaching content as a whole, and creates an atmosphere of attaching importance to practical teaching in the school content. At the same time, carry out practical teaching activities, strengthen cooperation with social enterprises, create real social practice space for students, let students fully experience the sense of accomplishment and satisfaction in learning, effectively stimulate students' interest and improve learning effects; Finally, through practical teaching, students' ability and speed of transforming theory into practice can be improved, the second leap of cognition can be realized, the advantages of case teaching can be fully displayed, and practical design cases can be continuously introduced into classroom teaching, so as to give full play to the guiding role of modern education mode in contemporary education.

\subsection{Organize design training camps, expand cross-disciplinary cooperation, and expand the scope of visual design creativity}

The online and offline interactive teaching mode of cloud classroom intelligent platform breaks the boundary between time and space. The online and offline interactive teaching of university visual communication design course has changed the original teaching environment to a great extent, overcome the deficiency of single teaching form of traditional university visual communication design major, and realize the combination of classroom teaching and multimedia internet. On the basis of reasoning, the theoretical system is constructed. Students digest the theory in the process of doing exercises, and find convincing examples in practice. Students will be 
more recognized for the theory, have a deep understanding of the theory, and have more methodology. The two are complementary and mutually confirmed.

Carry out practical teaching activities, strengthen cooperation with social enterprises, create real social practice space for students, let students fully experience the sense of accomplishment and satisfaction in learning, effectively stimulate students' interest and improve learning effects; Finally, through practical teaching, students' ability and speed of transforming theory into practice can be improved, the second leap of cognition can be realized, the advantages of case teaching can be fully displayed, and practical design cases can be continuously introduced into classroom teaching, so as to give full play to the guiding role of modern education mode in contemporary education.

\subsection{Establishing comprehensive cross-platform across specialties}

The construction of interdisciplinary comprehensive simulation training platform must aim at the training of compound talents. The gap between the single talent training mode and compound talent training demand in the past determines the functional orientation of interdisciplinary comprehensive simulation training platform.

First, establish a cross-disciplinary comprehensive simulation training platform, and bring students from different professional fields into the comprehensive simulation training through discipline competition or training, which must be based on the premise of realizing the integration and communication between different majors; Second, in order to meet the practical training needs of students of different majors, especially for the overlapping majors, the commonality of ability training, and the mutual cooperation between teaching units; Third, with the progress of technology, the informationization level of enterprises, posts and even businesses is constantly rising, and the requirements for information processing capabilities are also increasing. Therefore, only by continuously strengthening the informatization level of the cross-disciplinary comprehensive simulation training platform can the needs of training teaching be well met.

\subsection{Establishment of multidimensional evaluation mechanism}

Teachers who use massive open online course teaching mode can know students' mastery of knowledge points through MOOC platform, and learners can also know their mastery of knowledge points after submitting homework, and check for gaps in time to make up for shortcomings; Compared with traditional teaching mode, teachers can only rely on homework and mid-term and final exam results to evaluate learners [10]. The establishment of multi-dimensional evaluation mechanism can supervise and evaluate the whole learning process, but the learning effect is not obvious for learners with weak self-control ability. Moreover, MOOC teaching mode is difficult to monitor the examination process, and it is difficult to determine whether there is "substitute for learning" or "substitute for examination", and it is difficult to put an end to "cheating in examination".

\section{Conclusion}

The research on online and offline interactive teaching mode of cloud classroom intelligent platform has important practical significance and application value for changing the teaching status of visual communication design specialty in universities. Based on the scientific understanding of educational theory and practice, online and offline interactive teaching method came into being under the background of Internet economy era. It develops the teaching process through dynamic teaching mode, combining theory with practice mode and online and offline interactive teaching mode, which shows strong applicability in practice. The emphasis of visual communication design course lies in understanding, thinking and practice. The course aims at strengthening the combination of theoretical courses and practice, and displays the characteristics of MOOC lifelong learning and interest learning based on multi-dimensional interaction. It can improve the teaching effect by timely obtaining feedback and adjusting the course implementation plan.

\section{Acknowledgement}

The work described in this paper was supported in part by the Subject of the 13th Five-Year Plan of Educational Science of Guangdong in 2020 named Research on Application Strategies of Blended Teaching Model of Visual Communication Major in Colleges Based on Multidimensional Interaction Pattern (Grant No. 2020GXJK475).

\section{References}

1. Yoga Yu. research and practice of visual communication specialty under the teaching mode of "promoting teaching by competition and combining competition with learning" [J]. fine arts education research, 2018, 000(004):121.

2. Peng Tao. Research on the teaching mode of integrating network classroom and traditional classroom under the modern information technology environment-taking visual communication design as an example [J]. Boutique, 2020, 000(002):P.1-1.

3. Liu Congcong. The development and innovation of teaching mode of visual communication design specialty in colleges and universities $[\mathrm{J}]$. survey of education, 2020, 009(001):P.62-64.

4. Dawn, He Tingting. Exploration and practice of the teaching mode of video and TV courses for visual communication majors in local application-oriented universities — Taking the course of "Film and Television Post-production" as an example [J]. Literary Life Wenhai Art Academy, 2019, 
000(012):182-183.

5. Xi Libo. Exploration of Blended Teaching Mode in Visual Communication Design Professional Course [J]. Beauty and Times (Upper Xunkan), 2019, 000(003):107-109.

6. Liang Jinming. Exploration and Research on the Teaching Mode Reform of Visual Communication Design Specialty [J]. Curriculum Education Research: Research on Foreign Language Studies and Teaching Methods, 2019, 000(021):P.13-14.

7. Liu tianjiao. research on the mixed teaching mode of visual communication design under the background of big data [J]. art education research, 2020, no 233 (22): 154-155.

8. Huang Wei. Research on the reform of "studio system" teaching mode of visual communication design specialty $[\mathrm{J}]$. Art Education Research, 2019, 000(010):174-176.

9. Yang Tian. Applied Research on Online and Offline Mixed Teaching in Colleges and Universities [J]. International Education Forum, 2020, 2(7):1-2.

10. Han $\mathrm{Xu}$. research on the mixed teaching mode of visual communication design specialty $[\mathrm{J}]$. art works, 2019(35):109-110.

11. Jia Q. A brief study on the implication of constructivism teaching theory on classroom teaching reform in basic education[J]. International Education Studies, 2010, 3(2): 197-199.

12. Opletin A A. Formation of self-development competence of student"s personality by means of physical culture[J]. Theory and Practice of Physical Culture, 2013 (10).

13. Eigen D, Fergus R. Predicting depth, surface normals and semantic labels with a common multi-scale convolutional architecture $[\mathrm{C}] / /$ Proceedings of the IEEE international conference on computer vision. 2015: 2650-2658.

14. Song Xiaohuan, Liu Juan, Zhang Yawen. An Analysis of the Effect of Multi Dimensional Interaction Teaching Model on College English TeachingAction research based on two universities in Shaanxi [J]. The Guide of Science \& Education, 2017(02):9295.

15. Liu Jie. Research on The Blended Teaching Mode of College English Based on Cloud Platform[J]. Overseas English, 2020(16): 269-270.

16. Xu Xiujuan. Curriculum Reform and Practice Based on CDIO and SPOC Blended Teaching ModeTaking Comprehensive Training of Real Estate Development as an Example[J]. Vocational Technology, 2019, 018(007):34-38.

17. Matosas-Lopez L, Aguado-Franco J C, Gomez-Galan J. Constructing an Instrument with Behavioral Scales to Assess Teaching Quality in Blended Learning Modalities[J]. NAER - Journal of New Approaches in Educational Research, 2019,8(2):142-165.

18. Xu Lihong. An Empirical Study on the Reform of English Teaching Mode in the Transitional Period of
Private Universities--A Case of the English Experimental Class of Wuhan Qingchuan University [J]. 2019(35): 49-52.

19. Jinzhao C, Shan L, Guoqiang H, et al. Blended Teaching Reform and Practice of Fermentation Engineering Curriculum[J]. Farm Products Processing, 2019(06): 88-89+92.

20. Boysen G A. The multidimensional nature of teaching and student evaluations: commentary on students' judgements of learning and teaching effectiveness ScienceDirect[J]. Journal of Applied Research in Memory and Cognition, 2020, 9(2): 152-156.

21. Lin T J, Nagpal M, Vanderheide J, et al. Instructional patterns for the teaching and learning of argumentative writing in high school English language arts classrooms[J]. Reading and Writing, 2020, 33(10):2549-2575.

22. Lourdes Cardozo-Gaibisso, Kim S, Buxton C, et al. Thinking beyond the score: Multidimensional analysis of student performance to inform the next generation of science assessments[J]. Journal of Research in Science Teaching, 2020, 57(6): 856-878. 